\title{
Histopathological study of non-neoplastic skin lesions in a tertiary care center
}

\author{
Vijayasankar S. ${ }^{1}$, Rohit Mathew L. ${ }^{2 *}$, Alavandhar E. ${ }^{3}$, Vijayalakshmi C. S. ${ }^{4}$ \\ DOI: https://doi.org/10.17511/jopm.2020.i06.05 \\ 1 Sridevi Vijayasankar, Associate Professor, Department of Pathology, Sri Muthukumaran Medical College and Hospital and Research \\ Institute, Chennai, Tamil Nadu, India. \\ 2* Lionel Rohit Mathew, Assistant Professor, Department of Pathology, Sri Muthukumaran Medical College and Hospital and Research \\ Institute, Chennai, Tamil Nadu, India. \\ 3 Ezhilvizhi Alavandhar, Professor, Department of Pathology, Sri Muthukumaran Medical College and Hospital and Research Institute, \\ Chennai, Tamil Nadu, India. \\ 4 Vijayalakshmi C. S., Professor and HOD, Department of Pathology, Sri Muthukumaran Medical College and Hospital and Research \\ Institute, Chennai, Tamil Nadu, India.
}

Introduction: Skin is the largest organ of our body. Non-neoplastic skin lesions are more common than neoplastic lesions. The histopathological study was done to know the prevalence of various non-neoplastic skin lesions of patients who attended the outpatient department of dermatology over a period of three years from Jan 2016-Dec2018. Materials and Methods: In this study total of 209 cases of skin lesions were taken over a period of three years. The diagnosis of these skin lesions was confirmed by histopathological examination with routine hematoxylin and eosin stain. Results: A total of 209 cases of non-neoplastic lesions were taken for the study. Out of these lesions, 63 cases $(30.14 \%)$ were non-infectious - vesiculobullous, 54 ( $25.84 \%)$ were reported under the category of infectious etiology, 41 cases (19.62 \%) of non-infectious erythematous papulosquamous diseases, 13 cases $(6.22 \%)$ of inflammatory disorders, $10(4.78 \%)$ cases showed connective tissue disorders. $8(3.83 \%)$ cases were reported as vasculitis and 2 cases $(0.96)$ of fungal origin. 18 cases come under the miscellaneous category that was correlated clinically and were treated. Conclusion: In the present study of non-neoplastic skin lesions, non-infectious vesiculobullous diseases were more common. Pemphigus Vulgaris was the most common lesion. The non-neoplastic skin lesions were most commonly seen in males than females in our population of the study.

Keywords: Histopathology, Haematoxylin and eosin, Non-neoplastic skin lesions, Noninfectious vesiculobullous diseases

Corresponding Author

Lionel Rohit Mathew, Assistant Professor, Department of Pathology, Sri Muthukumaran Medical College and Hospital and Research Institute, Chennai, Tamil Nadu, India.

Email: yamahalion@gmail.com

\section{How to Cite this Article}

Vijayasankar S, Mathew LR, Alavandhar E, Vijayalakshmi CS. Histopathological study of nonneoplastic skin lesions in a tertiary care center. Trop J Pathol Microbiol. 2020;6(6):395-400.

\section{Available From}

https://pathology.medresearch.in/index.php/jopm/ar ticle/view/470
To Browse

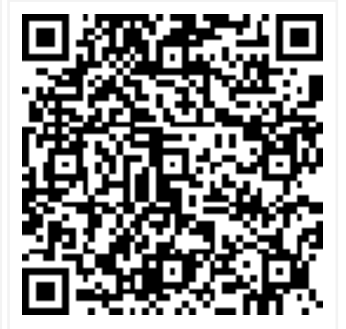

Manuscript Received 2020-07-09

Conflict of Interest No

Review Round 1
2020-07-26
Funding
Nil

Review Round 1

$\mathrm{Nil}$

Review Round 2
2020-08-10
Ethical Approval
Yes

Review Round 2

Yes
Review Round 3

Plagiarism X-checker $7 \%$
Accepted 2020-08-26

() 2020 by Sridevi Vijayasankar, Lionel Rohit Mathew, Ezhilvizhi Alavandhar, Vijayalakshmi C. S. and Published by Siddharth Health Research and Social Welfare Society. This is an Open Access article licensed under a Creative Commons Attribution 4.0 International License https://creativecommons.org/licenses/by/4.0/ unported [CC BY 4.0]. 


\section{Introduction}

Many studies have shown a high prevalence of skin disorders in developing countries, the histopathological spectrum of which has been highly variable [1]. The skin pattern varies geographically and also in different states of the same country. In India, dermatological diseases are one of the most common health problems [2].

But the skin diseases are not counted as a significant problem because they are mostly benign and not life-threatening and so low priority is given. The-neoplastic skin lesions form the majority of the morbidity from skin diseases $[2,3]$.

The separation of each skin case becomes important because the treatment and prognosis tend to be disease-specific. The punch biopsy is generally the most useful procedure, as it is quick to perform, convenient and it is the most common technique for definitive diagnosis.

Mostly full-thickness sample of skin is obtained in punch biopsy and the pathologist gets a good view of the epidermis, dermis, and most of the time the subcutis also. Clinical features of the skin lesions vary as papules, macules, nodules, hypopigmentation, and hyperpigmentation.

Clinical presentation can be common for various skin lesions but different histopathological pictures will be present which definitely require a histopathological examination for confirmation as treatment varies for different lesions. Correlation between the clinical and histopathological diagnosis is often essential for formulating the diagnosis [4].

Histopathology is the gold standard in providing an accurate diagnosis for a variety of skin lesions [5]. Early diagnosis of skin lesions by histopathological examination can prevent further infections, complications, better treatment, and early recovery. Separation and histopathological diagnosis of each skin lesions are important because the treatment and prognosis tend to be specific for each different skin lesions.

The aim of the present study is to analyze the prevalence of various non-neoplastic skin lesions in our tertiary care center hospital, the role of histopathology in diagnosing various non-neoplastic skin lesions, and to classify them into various categories according to their histopathological features which helps in better management of patients.

\section{Materials and Method}

Setting: The study was conducted in the Department of Pathology, Sri Muthukumaran Medical College, Hospital and Research Institute, Chikkarayapuram, Mangadu, Chennai, Tamil Nadu, India

Duration: January 2016 to December 2018

Type of the study: Retrospective type of study

Sampling Methods: A total of 209 cases of nonneoplastic skin lesions were collected from the hospital and analyzed in our pathology department. All biopsy tissue specimens fixed in formalin were subjected to gross examination and all dimensions were taken. A complete detailed history of the patients was taken down from the request provided by the dermatologist.

Inclusion criteria: All the non-neoplastic skin lesion biopsy specimens presenting in our department over a period of January 2016 to December 2018 were included in this study.

Exclusion criteria: Normal skin biopsies and neoplastic skin lesions were excluded from this study.

Data collection procedure: Data such as name, age, gender, clinical presentation, and history was recorded from the request. The histopathological examination of the skin biopsy was done on 4micron thin paraffin-embedded sections stained with hematoxylin and eosin ( $\mathrm{H}$ and $\mathrm{E})$. Special stains were done as and when desired. Histopathological diagnosis was correlated with the clinical diagnosis. The skin lesions were classified under various nonneoplastic categories according to the morphology of the lesions.

Ethical consideration and permission: The study was conducted in accordance with the ethical standards of the institution.

Statistical analysis: Results were tabulated and subjected to statistical analysis. Statistical analysis was done by calculating the number and percentage of the incidence in various age groups, in sexes, types of lesions, and also the comparison with other studies.

\section{Result}

In the present study, 209 cases of non-neoplastic skin lesions were analyzed and categorized into 
Different non-neoplastic entities over a period of three years. (Table 1) Out of 209 cases, 119 were males and 90 females with male patients more than females (Table 2). Non-neoplastic skin lesions were common in 40-60 years of age group. Among these, the commonest lesions were 63 cases of noninfectious vesiculobullous lesions in which 19 cases were reported as pemphigus Vulgaris and 11 patients had bullous pemphigoid features.

The mean age of presentation was 36 years for pemphigus lesions and was more common in male patients. Under the infectious category of 54 cases of granulomatous lesions, 28 cases were Hansen's disease which was more common and most frequently reported in males followed by 21 cases of cutaneous tuberculosis disease. The maximum number of cutaneous tuberculosis cases was seen in 21-48 years of age and common in males. Among the non-neoplastic cases, 41 (19.62\%) were reported under the category of non-infectious erythematous papulosquamous diseases, in which 14 cases were lichen planus which was most common followed by psoriasis. 13 cases of Inflammatory diseases followed by 10 cases of connective tissue disorders.

8 cases $(3.83 \%)$ were reported under medium and small-vessel vasculitis which was found to be the second least cases in the present study. 2 cases were reported under the fungal infection in the present study (Table 3). 18 cases were not able to be categorized because of partial treatment and overlapping features, these cases were brought under the miscellaneous category and correlated with the the clinical picture.

Table-1: Type of skin lesions.

\begin{tabular}{|l|l|}
\hline \multicolumn{1}{|c|}{ Type of skin lesion } & \multicolumn{1}{c|}{ Number } \\
\hline Non-neoplastic lesions & 209 \\
\hline
\end{tabular}

Table-2: Gender incidence of skin lesions.

\begin{tabular}{|l|l|l|}
\hline \multicolumn{1}{|c|}{ No. of cases } & \multicolumn{1}{|c|}{ Male } & \multicolumn{1}{c|}{ Female } \\
\hline 209 & 119 & 90 \\
\hline$\%$ & 56.94 & 43.06 \\
\hline
\end{tabular}

Table-3: Distribution of non-neoplastic skin lesions.

\begin{tabular}{|l|l|l|l|l|}
\hline \multicolumn{1}{|c|}{ Type of skin disorder } & Male & Female & Total & $(\%)$ \\
\hline Non-infectious vesiculobullous & 36 & 27 & 63 & 30.14 \\
\hline Infectious lesions & 31 & 23 & 54 & 25.84 \\
\hline Non-infectious erythematous papulosquamous & 25 & 16 & 41 & 19.62 \\
\hline Inflammatory disorder & 8 & 5 & 13 & 6.22 \\
\hline Connective tissue disorders & 5 & 5 & 10 & 4.78 \\
\hline Vasculitis & 5 & 3 & 8 & 3.83 \\
\hline
\end{tabular}

\begin{tabular}{|l|l|l|l|l|}
\hline Fungal & 2 & 0 & 2 & 0.96 \\
\hline Miscellaneous & 10 & 8 & 18 & 8.61 \\
\hline Total & 122 & 87 & 209 & \\
\hline
\end{tabular}

\section{Discussion}

In this retrospective study conducted at the department of pathology, a total of 209 cases were analyzed. Kumar et al [1] analyzed 232 cases of non-neoplastic skin lesions and in a study by Neetu Goyal et al 270 non-neoplastic cases were studied. The histopathologic study of skin lesions has a smaller number of cases when compared to clinically-based studies of non-neoplastic skin lesions $[6,7]$. Out of 209 cases, there were 119 cases $(56 \%)$ of males and 90 cases $(44 \%)$ of females which were similar to the study done by Singh et al in which $54.5 \%$ were males and $45.5 \%$ were females, Mehar et al also showed that $56 \%$ were male and $44 \%$ cases were female. The sex distribution pattern revealed that most of the patients were males, which is similar to the study done by Rakesh Mehar et al [3] and Veldhurthy et al. The age distribution pattern in the study showed that the youngest patient was 11 years and the oldest was 83 years. Most patients were falling under the age group of 40 to 60 years; similar findings were also shown by R. Singh et al with $36.06 \%$ in their study [8].

The majority of cases in the present study were vesiculobullous lesions with $30.14 \%$ which is similar to the study done by Gireesh V. Achalkar et al in which $54 \%$ of cases were vesiculobullous lesions when compared to other lesions [Figure 1-4]. Among the 63 cases of vesiculobullous lesions, pemphigus Vulgaris was more common followed by bullous pemphigoid which was similar to the study done by Anupama Raj Karattuthazhathu et al which showed 36 cases of Pemphigus Vulgaris and 20 cases of Bullous pemphigoid.

In the present study $25.84 \%$ of Infectious diseases which include granulomatous lesions, were the second most common lesion which is similar to Gireesh V. Achalkar et al findings which had $22 \%$ of the lesion. According to Narang et al and R Singh et al study among the granulomatous lesions, leprosy was the most common followed by tuberculosis $[2,8,9]$. R Singh et al study showed 12 cases of leprosy lesion among 26 granulomatous lesions these findings were similar to the present study. Granulomatous lesions were most commonly seen in males than females similar to the R Singh study. Among the leprosy cases, tuberculoid leprosy was 
Seen more commonly than other types which are similar to studies reported by Deepti Agarwal et al and Gautam $\mathrm{K}$ et al $[9,10]$. In the present study 41cases of papulosquamous diseases were found and were mostly seen in males with comparison to females which was similar to a study done by Veldhurthy VS et al [11] which showed lichenoid lesions were the commonest histopathological findings. Lichen planus was more commonly occurring among the papulosquamous lesions which correlated with the study done by Veldhurthy VS et al and S. D. Chavhanet al [12] these lesions also showed male predominance. In the present study, $6.22 \%$ of inflammatory disorders cases were seen moe in males followed by $4.78 \%$ connective tissue disorders which showed equal distribution in males and females. $3.83 \%$ of medium and small-vessel vasculitis cases are the second least number and had male predominance and small-vessel vasculitis was common among the vasculitis cases.

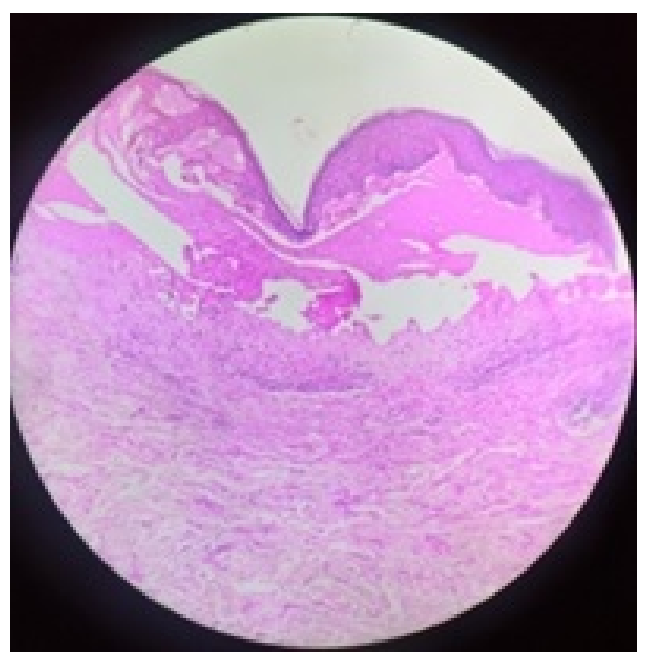

Fig-1: H and E. 4x - Dermatitis herpetiformis: Subepidermal bulla with eosinophils.

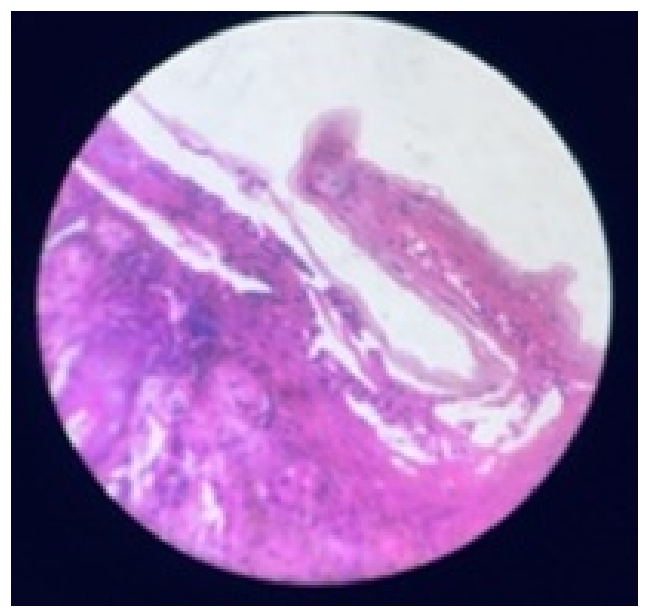

Fig-2: H and E. 4x - Pemphigus Vulgaris: Intra epidermal blister with chronic inflammation.

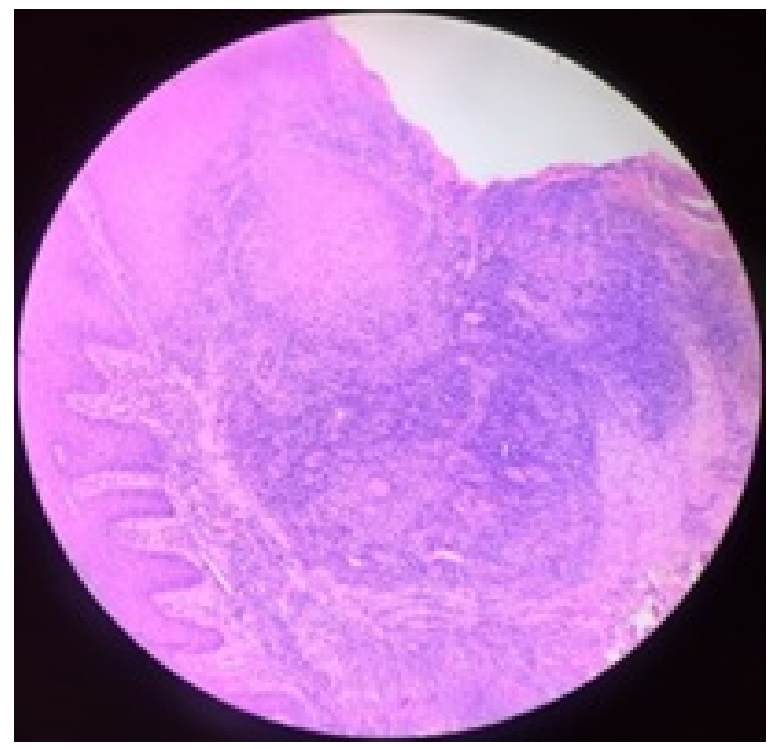

Fig-3: $H$ and E. 4x - Lupus vulgaris: Dermis with granuloma, giant cell, and chronic inflammation.

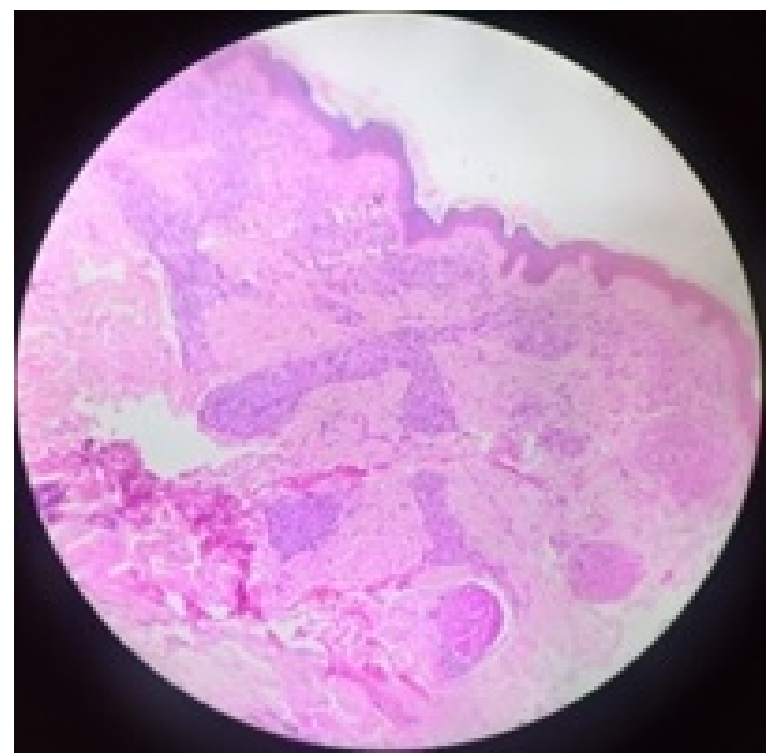

Fig-4: $H$ and E. 4x - Lepromatous leprosy: Atrophic epidermis with dermis showing the collection of histiocytes.

\section{Limitation}

Complete clinical details were difficult to collect and also follow up data could not be obtained from all the patients for the study.

\section{Conclusion}

In the present study, 209 cases, of non-neoplastic skin biopsies were taken. The sex distribution patte- 
$\mathrm{Rn}$ revealed a male preponderance. The most common skin lesion reported was noninfectious vesiculobullous lesions with pemphigus Vulgaris being the commonest lesion followed by bullous pemphigoid. Hansen's disease is still the second most common skin disorder in the present study. Fungal infections were the least common lesions. Histopathology was helpful in making the definitive diagnosis of non-neoplastic skin disorders in 91.39 $\%$ cases and the rest of the cases were correlated clinically. This emphasizes the importance of histopathology in diagnosing non-neoplastic skin disorders.

\section{What does this study add to existing knowledge}

- Prevalence of various non-neoplastic skin lesions in our tertiary care center

- Role of histopathological examination in diagnosing non-neopastic skin lesions and classifying them for treatment purposes.

\section{Author's contributions}

Dr. Sridevi Vijayasankar: Study concept, data collection, data analysis

Dr. Lionel Rohit Mathew: Data analysis, manuscript preparation

Dr. Ezhilvizhi Alavandhar: Manuscript preparation, study design

Dr. C.S. Vijayalakshmi: Study concept, study design

\section{Reference}

01. Kumar V, Goswami HM. Spectrum of nonneoplastic skin lesions- a histopathological study based on punch biopsy. Int J Cur Res Rev. 2018; 10(6)43-48.

doi:10.7324/IJCRR.2018.1069 [Crossref]

02. Narang $S$, Jain R. An evaluation of histopathological findings of skin biopsies in various skin disorders. Ann Pathol Lab Med. 2015;02(01)42-46.

[Crossref]

03. Yahya $H$. Change in pattern of skin disease in Kaduna, North-Central Nigeria. Int J Dermatol. 2007;46(9)936-43.

doi: $10.1111 /$ j.1365-4632.2007.03218 [Crossref]
04. Goyal N, Jain P, Malik R, Koshti A. Spectrum of Non Neoplastic Skin Diseases- A Histopathology Based Clinicopathological Correlation Study. Sch J App Med Sci. 2015;3(1F)444-449.

[Crossref]

05. Achalkar GV. Clinico-pathological evaluation of non-neoplastic and neoplastic skin lesions- A study of 100 cases. Indian J Pathol Oncol. 2019;6(1)118-122.

doi: 10.18231/2394-6792.2019.0021 [Crossref]

06. Mehar R, Jain R, Kulkarni CV, Narang S, Mittal $M$, Patidar $H$. Histopathological study of dermatological lesions - A retrospective approach. Int J Med Sci Public Health. 2014;3(9)1082-1085.

doi: 10.5455/ijmsph.2014.190620142 [Crossref]

07. Ogunbiyi AO, Owoaje E, Ndahi A. Prevalence of skin disorders in school children in Ibadan, Nigeria. Pediatr Dermatol. 2005;22(1)6-10.

doi: 10.1111/j.1525-1470.2005.22101.x [Crossref]

08. R Singh, K Bharathi, R Bhat, C Udayashankar. The Histopathological Profile of Non-Neoplastic Dermatological Disorders with Special Reference to Granulomatous Lesions - Study At A Tertiary Care Centre In Pondicherry. Int $\mathrm{J}$ Pathol. 2012;13(3)1-6.

[Crossref]

09. Agarwal D, Singh K, Saluja KS, Kundu PR, Kamra H, Agarwal A. Histopathological Review of Dermatological Disorders with a Keynote to Granulomatous Lesions- A Retrospective Study. Int J Sci Study. 2015;3(9)66-69. doi: $10.17354 /$ ijss/2015/557 [Crossref]

10. Gautam K, Pai RR, Bhat S. Granulomatous lesions of the skin. J Pathol Nepal. 2011;1(2)8186.

doi: 10.3126/jpn.v1i2.5397 [Crossref]

11. Veldurthy VS, Shanmugam C, Sudhir N, Sirisha O, Motupalli CP, Rao N, Reddy SR, Rao N. Pathological study of non-neoplastic skin lesions by punch biopsy. Int $\mathrm{J}$ Res Med Sci. $2015 ; 3(8) 1985-1988$.

doi: $10.18203 / 2320-6012 . i j r m s 20150313$ [Crossref] 
12. Chavhan SD, Mahajan SV, Vankudre AJ. A Descriptive Study on Patients of Papulosquamous Lesion at Tertiary Care Institute. MVP J Med Sci. 2014;1(1)30-35.

[Crossref] 